\title{
The Efficiency of Using Pictures in Teaching Speaking Skills of Non-native Arabic Beginner Students
}

\author{
Mohammad H. Al-khresheh", ${ }^{1, *}$ Ahmad Khaerurrozikin ${ }^{2}$, Abdul Hafidz Zaid ${ }^{2}$ \\ ${ }^{1}$ Department of English Language, Northern Border University, Saudi Arabia \\ ${ }^{2}$ Department of Arabic Language, University of Darussalam Gontor, Indonesia
}

Received October 20, 2019; Revised January 10, 2020; Accepted January 17, 2020

Copyright $(2020$ by authors, all rights reserved. Authors agree that this article remains permanently open access under the terms of the Creative Commons Attribution License 4.0 International License

\begin{abstract}
Communication remains one of the ultimate objectives of learning any language. Speaking is one of the most basic language skills that should be well mastered by foreign language learners. It is considered one of the most complex aspects of language learning, especially for beginners. The use of pictures in language has been accredited to immense success and improvement in language learning. Therefore, this study aims at investigating the effectiveness of using "picture media" in improving the speaking skills of a group of 20 Indonesian, non-native Arabic speakers. In order to collect data, a combination of two methods was used namely, observation and a questionnaire designed for the purpose of examining the effectiveness of using pictures as a teaching aid. The findings of this study confirmed that picture media is an indispensable component in improving Arabic speaking skills immensely. The analysis revealed that the subjects of this study reported better results after pictures use.
\end{abstract}

Keywords Arabic Language, Speaking Skill, Picture Media, Language Learning and Teaching

\section{Introduction}

Arabic is considered as one of the world's most widely spoken languages. It is a macro-language that includes 30 modern varieties. It mostly belongs to the Semitic language family. There are millions of people who speak Arabic around the world. Arabic has a great role in the Islamic faith Muslims view it as the language of the Holy Quran [7].

Indonesia is one of the countries where Arabic is widely used. The study of Arabic language as a subject is a long-time practice in Indonesian schools. However, it is plagued with several problems, mainly due to the methods of teaching and the attitude of students to learning. These problems which will be discussed below have led to students, who are certified to have completed the subject but in reality, cannot speak the language. A major problem is the lack of interest on the part of the student. This has led to a situation where only a few students actively participate in the class and the rest of the class ride along without fully understanding the subject. They rely on the few active students to pass their assignments and exam [18].

This lack of interest can be blamed on many things, there is no motivation for the students to learn Arabic and since they are not aware of the benefits of learning the language, they consider it a burden. Most of the students also lack the confidence to speak the language fluently. Because it is not their first language, they are prone to making mistakes which could generate jest and laughter from their friends; they therefore totally avoid practicing the language which is the surest way to master it. Furthermore, the methods of teaching employed by the teachers also play a key factor in undermining the study of the language. Teachers usually teach the subject in an abstract and impractical way which appears confusing to the students. They quickly lose interest in the subject due to this method of teaching $[4,13,16 \mathrm{a}]$.

A summation of these problems has led to failures of students in examinations on the Arabic language. Getting the average score needed to pass the subject is so difficult for students that most times, there is a need to do a remedial program for every single material to upgrade the scores of students. With these numerous problems facing the study of the Arabic language, researches have been carried out to see how to improve students' performance and improve their ability to communicate in the language.

One of the methods is through the use of visual media. It was discovered that using visual media in the process of teaching aids learning greatly. This is so because most people are visually oriented. According to researchers, 
people learn over $80 \%$ of what they see compared to the $10 \%$ they learn from just listening. It was also discovered that people remember $50 \%$ of what they see and hear compared to $20 \%$ of what they only hear. Furthermore, visual media is the best way to pass information across to children and young learners who find it easier to understand concrete and physical concepts more than abstract ones. This means that early exposure to visual media will not only make it easier for kids to fully learn the basics of the language, it would also help them when they start learning the advanced and abstract stages as they can incorporate their previous experiences $[1,18$, 20].

Visual media also makes the learning process more fun and entertaining. Instead of just staring at abstract letters on the board, students have pictures and visual cues to focus on. This makes the class more interesting, and the students are more motivated to participate and improve their abilities. Given this, this study aimed at assessing the effectiveness of picture media use in improving the speaking skill on a group of Indonesian, non-native Arabic speakers.

\section{Literature Review}

Teaching foreign languages is an uphill task. It is filled with various problems. Learning a new language might be accompanied with several linguistic and nonlinguistic difficulties. Finding solutions to cope up with such difficulties becomes not only the teachers' responsibility but also the researchers of second language acquisition $[2 b, 5,6]$.

There are four major skills that ought to be well-mastered by language learners. They are listening, speaking, reading, and writing. Speaking has been long considered the most critical, important and difficult skill due to the fact that second or foreign language learners measure their success in language learning through the mastery of this skill. It allows people to form connections, influence diverse decisions, and inspire alteration. The capability to development in the world would be practically impossible without communication skills. As human beings, we are programmed to speak before we read and write. Arabic speaking is a difficult task because certain components such as grammar, pronunciation, and vocabulary should be well mastered [17, 21, 23].

Pictures as a teaching aid are generally employed in teaching and learning processes. It is defined as a visual illustration that is painted or snapped and turned into a flat surface [24]. Chesla [14] reveals that "Because humans are very visually oriented, we tend to remember much better when we can see things as well as hear or read them (p. 142)." It is believed that language learners get more dynamic when interesting teaching aids that stimulate their attention are introduced. Previous studies show that picture, as one of these influential teaching aids, is the most compelling pedagogy for language learning. This teaching technique stimulates students' cognition, improves their comprehension, increase their interest and motivation towards language learning, and gives them more confidence to speak. This technique can also arouse students' discussion and elucidation of the topic. Pictures can increase students' participation as well as build a better attitude towards language learning $[8,11,17]$.

Brown [12] considered the picture technique as an influential method to bring out students' oral language performance at intensive and extensive levels. He goes on to say that intensive and extensive forms of teaching might make possible monologues and rhymes correspondingly, where firm forms of the language can be perused by learners.

Rochmah [22] pointed out that pictures furnish a high-quality effect on the students' reading comprehension of texts. In writing, Azhari [9] declared that his students' writing skills got improved after using different pictorial writing activities. Anshori [cited in 18] asserted cue cards as one of the instructional media that help students increase their speaking ability. Lukitasari [19] conducted a study on learners' approaches to conquering their speaking problems. The findings of his study confirmed that there are plenty of difficulties that language learners face, and speaking was the most problematic one.

The above literature shows the significance of picture media in the teaching and learning process of language; pictures make rapid changes in students' though process which leads toward a successful learning journey. This method excites students to think about the multiple complex nuances of a difficult language in an expedient way. Thus, this study aims at filling this gap by providing a qualitative case study on the use of picture learning in teaching Arabic.

\section{Research Method}

This study is qualitative descriptive in nature. It uses a cross-sectional research design for the purpose of getting a deeper understanding of developing effective problem formulation in the application of picture learning in language learning.

A group of 20 Indonesian non-native Arabic speakers were requested to take part in this study. This sample was purposely selected. The subjects were homogeneous in terms of their socio-economic and educational background. University Indonesian students are required to speak Arabic, both inside and outside of lectures. This is because, in the context of Arabic learning, speaking includes basic skills that must be mastered by students and is one of the most important objectives of foreign language learning. Some Indonesian universities use an 
Arabic language program that lasts for almost a year and is relatively short for beginner students. One of its main goals is to maximize speaking ability.

A combination of these two methods was used to achieve the main objectives of the study. Classroom observation and a survey were used to assess the effectiveness of the use of pictures in improving the subjects' speaking skills. The use of these methods was particularly crucial to the study as they bore a variety of advantages. Observation is almost certainly the simplest and easiest method of data collection because neither much knowledge nor time is necessitated. The most important benefit of utilizing questionnaires is that more people can be reached relatively easily, and it's cost-effective. The secrecy of questionnaires allows people to feel frank with their answers. The answers are reasonably simple to analyse $[15,16]$.

Both instruments were self-designed. The panel's method was employed to check the content validity of these instruments. Scientifically, this method is considered the best in terms of checking content validity [10]. The questionnaire that is designed for the purpose of this study consisted of 10 questions. It was distributed among the subjects after the researchers had finished the experimental part that included two lessons. The researchers evaluated the subjects in both lessons according to a set of items that were categorized under four main criteria. The researchers observed the subjects indirectly. Although there are some disadvantages of indirect observation, it seemed appropriate for the main objective of the current study. One of the basic benefits of indirect observation is that the data of other observers can be easily analysed by the researchers in light of the contemporary situation. Another advantage is that it is simple to put together inferences based on the studies of other researchers.

This research focuses on the participant's self-reported experiences and assessments and how this is related to their learning experiences. Therefore, a questionnaire survey was utilised to collect relevant data about the picture learning system. In order to get accurate responses from the subjects, the researchers explained the objectives and significance of the study to the participants in order to encourage them to respond effectively to the questionnaire's items.

\section{Analysis and Findings}

A descriptive statistical method was employed for analysing the data by using Microsoft Office Excel. The analysis of both instruments used in this study revealed that a group of 20 Indonesian university students, who learn Arabic as a second language, were involved in this study.

In order to find out whether using pictures in teaching Arabic speaking has a good impact on the subjects' oral performance, the researchers conducted two experimental lessons at different times in order to discover the effectiveness of instructional media using images in improving their Arabic speaking skills. In the first experimental lesson, the researchers followed the traditional teaching approach, and in the second lesson, they used some pictures designed for the purpose of attracting the subjects' attention to the lesson and encouraging them to speak. The researchers found that using pictures had a great role in raising the level of their comprehension, which in turn was reflected in their speaking skills. The subjects' comprehension and performance during the two experimental lessons were evaluated though a classroom observation by the researchers of this study who evaluated the subjects according to four basic criteria namely pronunciation, vocabulary, grammar and understanding, and comprehension. Under each criterion, there was a group of items that help the researchers in the process of evaluation. Figure 1 below presents the subjects' scores in the traditional lesson and in the pictorial one. It could be noticed that the subjects' scores in the pictorial Arabic speaking lesson were higher than those in the traditional one. There was a period of time between the two lessons. This procedure was done to give the subjects sufficient exposure to this new teaching technique. 


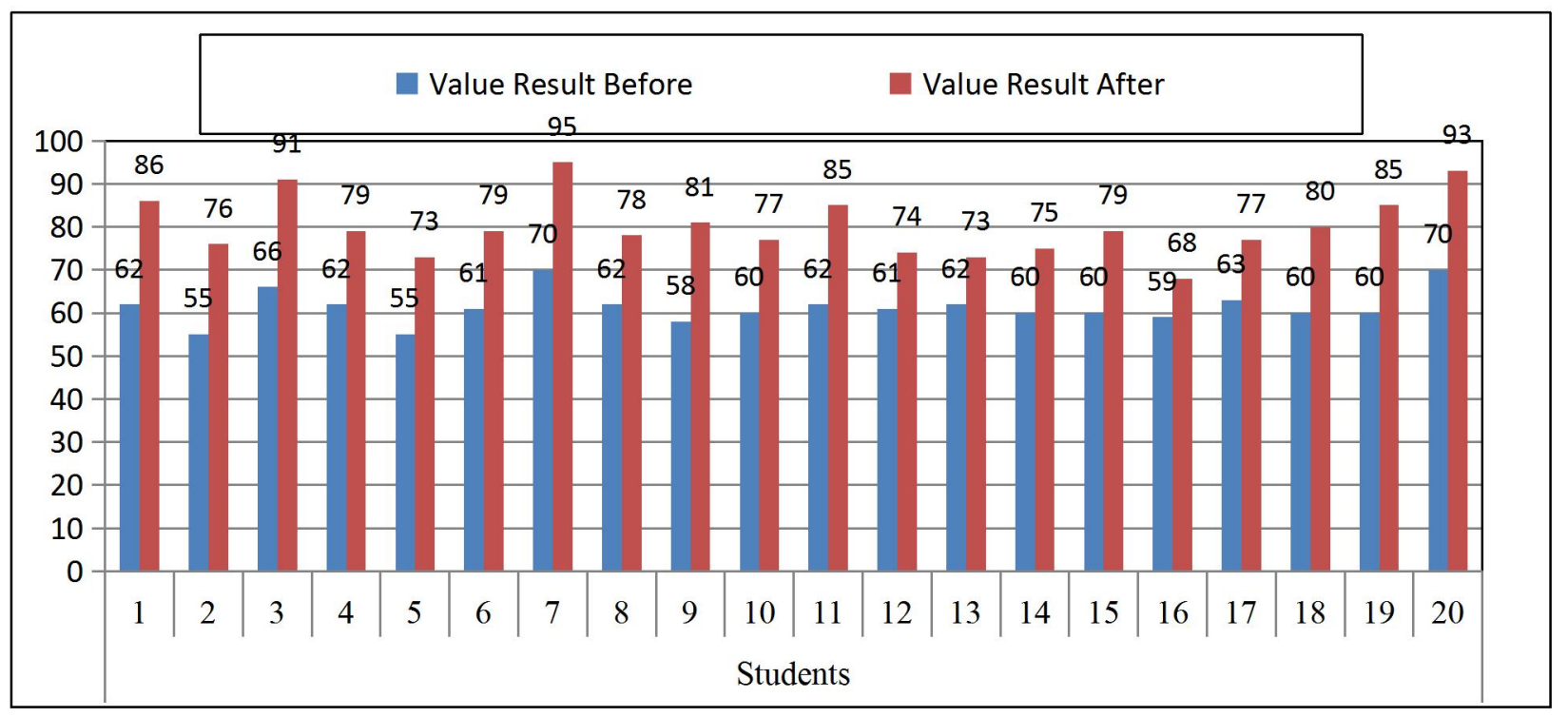

Figure 1. The subjects' scores before using the pictures and after

As stated earlier, a closed-ended questionnaire was administered to 20 students after the observation process. The questionnaire composed of a 5-point "Likert scale", where $1=$ strongly agree, $2=$ agree, $3=$ neutral, $4=$ disagree, and $5=$ strongly disagree. The researchers explained the questionnaire's questions clearly to the subjects, and then, they were asked to complete it.

Question 1: Does using pictures help you use more grammatical rules while structuring Arabic sentences?

The average score of the question was $90 \%$ (strongly agreed). This means that the highest percentage of students feel that they can improve their speaking skills through the use of the pictorial learning system. Although focusing mainly on grammar may prevent language learners from being able to speak confidently but using pictures can highly help beginners to get the basic grammar, which is a necessity. Structuring simple Arabic sentences is a must to start speaking. Learning basic grammar is very important in enhancing accuracy. Teaching grammatical structures throughout pictures helps learners expand a practice of thinking reasonably and plainly and will become more precise while using language.

Question 2: Is using pictures very interesting to you?

The average score of this question was $84 \%$

(agreed). This means that using pictures makes students feel interested in paying much attention to the class that was being taught. To be interested in something means to be motivated to learn more about it. In the case of language learning, showing different pictures makes students more interested in exploring the topic in-depth; therefore, they become more energetic. Pictures stimulate their interest to participate and speak more.

Question 3: Does using pictures help students to compile vocabularies into Arabic sentences and be able to know how to use them in speaking?

$94 \%$ of the subjects strongly agreed that the use of pictures could help them in combining vocabulary into Arabic sentences, and they can find out how they are used in speaking. Lack of vocabulary is regarded as one of the main reasons that affect second or foreign language learners' oral performance. The subjects reported that using pictures helped them to stop thinking of their mother tongue. Vocabulary is crucial to speaking success. Having sufficient vocabulary improves learners' comprehension and all areas of communication. Using pictures enriches learners' vocabulary. This might also enhance their oral performance.

Question 4: Does using pictures enhance your comprehension of Arabic?

The average score of this question was 96\% (strongly agreed). The subjects agreed that the use of pictures could assist students in understanding speaking lessons without much difficulty. This high percentage indicates that the use of this strategy is significant to improving the level of understanding. Pictures usages have been proved to break down several language barriers. As learners' skills develop, pictures serve as the ideal technique to get better comprehension.

Question 5: Does using pictures give students more confidence and encouragement to speak Arabic in class?

$82 \%$ of the subjects agreed that the use of pictures could help them practice speaking Arabic effectively and confidently. It is well known that the first step to speaking a language is to have self-confidence, which comes only from practice. Practice is the magical key to speaking any language successfully and efficiently. No one can acquire the competence of any language without practice. The 
subjects agreed that using pictures strengthens their confidence to speak Arabic freely. Confidence comes when learners are able to express their own ideas without hesitation and fear. Using pictures in the process of learning Arabic language can be extremely helpful for beginners as it gives them more confidence to speak.

Question 6: Does using pictures make it easier for students to tell stories?

$98 \%$ of the subjects strongly agreed that the use of pictures helped them tell Arabic stories. In the classroom observation, the subjects were asked to have a look at the pictures which were designed and classified into some parts; each part has certain events. The subjects were expected to think deeply in order to understand the event and then deliver it orally afterward. To further improve the level of motivation, they were asked to help each other to raise the level of communication. Storytelling through using pictures is a good strategy that helps second and foreign language learners speak more proficiently. This is because narrating stories makes students construct many sentences.

Question 7: Does using pictures encourage students to speak Arabic continuously?

The subjects of this study agreed with a percentage of $80 \%$ that the use of pictures can encourage them to speak Arabic continuously. The possible explanation of this percentage might be attributed to the fact that whenever a language learner feels that he/she has started breaking down language barriers inside the class, he/she will build more confidence that allows him/her to speak continuously.

Question 8: Does using pictures have an effect on remembering the lessons for a long time?

$94 \%$ of the subjects of this study strongly agreed that the use of pictures could help them remember the lesson for a long period of time. The ability of the students to remember what was learnt previously and integrate it into the next class is critical in any language learning. Using visual aids such as pictures inside any language classroom can make teaching more effective. Such teaching aids also help students to not only understand but also to remember concepts without difficulty. Previous research has proved that a conspicuous feature of human memory is that words are less remembered than pictures.

Question 9: Does using pictures make speaking skills enjoyable during the learning process?

$90 \%$ of the subjects strongly agreed that the use of pictures made speaking and learning enjoyable during the lesson. The subjects reported that they had much fun and felt more interested in speaking and expressing themselves as regards to the pictures' contents. This may indicate that when students enjoy a given subject, they will then have the incentive to learn more. Having such visual aids creates an interesting and stimulating teaching environment and reduces boredom.

Question 10: Does using pictures eliminate boredom in learning speaking skills?

$96 \%$ of the subjects strongly agreed that the use of pictures can eliminate boredom in learning how to speak. Boredom can be reduced when language learners understand what is being taught to them, and therefore, they become more active. Using pictures can surely eliminate boredom and help students in becoming more focused. This might be attributed to the fact that such teaching aids help students grasp the lessons promptly, create an interactive environment for students that promote and increase participation, clear perplexity, and offer instantaneous experiences.

Given this analysis, the overall score of the questionnaire distributed among the subjects of the study was $84.5 \%$, as presented in the following equation: Result Rating Average: $\frac{241}{285} \times 100 \%: 84.5 \%$. This value of $84.5 \%$ shows that students agree that the use of pictures is quite helpful and effective in improving speaking lessons.

\section{Discussion and Implications}

The results of this study revealed that using pictures as a teaching aid can highly improve the language learning process. Generally, subjects from the experimental group reported better results after the intervention than the control group. The results of the questionnaire confirmed that the subjects found using pictures to be more helpful for the reason that it helped them put a basis upon which to start speaking in Arabic more willingly than merely coping in the void of visual aids. This supports the claim that points out that pictures can decrease participation anxiety among second or foreign language learners and increase motivation. Consequently, pictures could be considered a starting point for students, which will ease their aptitude to speak. Second or foreign language learners might find it easier to understand what is being taught when visual support is included. This surely affects the way things are deduced.

The subjects have been reported to have immense results when using this technique of learning as compared to other techniques. This study has been able to identify the main problems with learning Arabic, which is that students tend to forget what they have learnt. Thus, the use of this technique alleviates this problem and makes students more focused and concentrated. The use of the picture model is critical in influencing and enhancing success of student's performance.

The researchers' observation before using pictures revealed that the subjects' anxiety level negatively affected their oral performance. This might be attributed 
to the fact that they do not have enough confidence to speak. Tanver [25] pointed out that anxiety lowers learners' speaking ability. It was also observed that the subjects use their first language to deliver the content. Al-khresheh [3] asserted that foreign and second language learners tend to use their mother tongue as a crutch to facilitate their language learning process without paying enough attention to how different the language is. The thing which makes them commit different errors, if not perfectly corrected, will lower their confidence and participation and stop them from speaking. Lack of vocabulary and fear of being despised were also observed as one of the main factors that hinder their speaking skills. Urrutia and Vega [26] affirmed that learners' oral performance can be approved if they learn more vocabulary. The subjects were also noticed to be less active in participation and communication with each other. Practise is the basic solution to improve their speaking skills. However, this might be attributed to their reduced confidence.

It was noticed that using pictures reduced the level of anxiety and made the subjects feel more comfortable in speaking without even referring to their mother tongue. Pictures can also help them enrich their vocabulary, which will encourage them to speak and enhance their oral performance.

It was found that pictures can facilitate a student's ability in learning how to compose sentences, in addition to being able to convey thoughts easily. Such teaching aids can help in the creation of a story that encourages them to speak, for example, about their daily routine. The researchers of this study created different stories about daily activities in a form of pictures, starting from waking up to the moment of sleep. They observed that the subjects were more motivated when it comes to speaking about their daily activities at home with the family, in the kitchen, in the yard, in the bathroom, at the mosque, and at school.

Stories describing daily activities make it easier for students to take part in storytelling, especially using Arabic. This is because such stories are related to situations that students experience daily. Stories, accompanied by picture media, can help students arrange sentences contained in the story. Students were able to associate one picture with another to form a complete story. This is why using picture media in stories is effective in helping students with speaking Arabic.

In learning how to speak, there are various models and speech exercises that have been developed by language experts. Each approach or method places emphasis on certain techniques. The audio-lingual method, for example, emphasizes the need to learn to memorize the dialogue model before entering into free dialogue. While the communicative method emphasizes the understanding of the dialogue model, including the function of each expression, as well as the context or situation, it then goes straight into the actual communication exercise

Giving assignments to students to tell stories is one way to find out their ability to speak accurately. While telling a story, there are two things students must master. They need to understand the elements of how to tell stories and how to choose the language, as well as what elements are told. The accuracy, smoothness, and clarity of the story will show students' speaking ability. Pictures can stimulate students' ability to speak. Concerning linguistic accuracy and extra-linguistic elements, the picture presented to students is a picture containing activities that reflect certain intentions or ideas. The picture in question is a picture that has a purpose or story that shows an event.

Using pictures, as one of the instructional media in teaching, is one of the most important techniques used inside foreign language classrooms to enhance students' speaking ability through showing pictures and assigning some students to speak about the pictures being viewed. This is done to strengthen students' memories further. Students should provide responses and then listen to the messages conveyed by the teacher. Another technique is that students read the content of certain stories in accordance with the pictures provided. Next, students imitate the contents of the story contained in the picture, one by one, until the picture is fully described.

\section{Conclusions}

This study aimed at assessing the efficiency of using pictures in the teaching of speaking skills for non-native Arabic beginner students. A combination of two methods was utilised. The findings confirmed that using pictures as a teaching aid can facilitate the Arabic language learning process in general and speaking in particular. This technique can also be considered an excellent method in improving the students learning ability as well as their performance in the class setting. Using pictures while teaching helps students to get rid of boredom, reduce language anxiety, provide more fun, helps them develop more confidence, and increase their motivation to speak. The data analysis confirmed that the subjects enjoyed adding in the pictures as they could draw their attention, expand their imagination, and create a more interesting teaching environment. As the study was conducted on a sample group of non-native Arabic speakers, a more in-depth one is highly suggested for future research, so the results can be generalized to other contexts.

\section{REFERENCES}

[1] Aldalalah, Osamah., Soon Fook Fong, and W. Ziad Ababneh. "Effects of Multimedia-Based Instructional 
Designs for Arabic Language Learning Among Pupils of Different Achievement Levels." International Journal of Human and Social Sciences 5.5 (2010): 311-317.

[2] Al-khresheh, Mohammad. "A review study of contrastive analysis theory." Journal of Advances in Humanities and Social Sciences, 2, 6, (2016B): 330-338.

[3] Al-khresheh, Mohammad. "A review study of error analysis theory." International Journal of Humanities and Social Science Research, 2, (2016A); 49-59.

[4] Al-khresheh, Mohammad. "A review study of interlanguage theory." International Journal of Applied Linguistics \& English Literature, 4, 3, (2015):124 - 131.

[5] Al-khresheh, Mohammad. "An investigation of interlingual interference in the use of 'and' as a syntactic coordinating structure by Jordanian EFL learners." European Journal of Social Sciences, 18, 3, (2011): 426-433.

[6] Al-khresheh, Mohammad. "Interlingual interference in the English language word order structure of Jordanian EFL learners." European Journal of Social Sciences, 16, 1, (2010): 106-113.

[7] Al-khresheh, Mohammad. The Misuse of Word Order in the Writing of Jordanian EFL Learners. Unpublished doctoral dissertation, University of Malaya, Kuala Lumpur, Malaysia. (2013).

[8] Al-Musawi, Ali, et al. "Perceptions of Arabic Language Teachers toward Their Use of Technology at the Omani Basic Education Schools." Education and Information Technologies 21.1 (2016): 5-18.

[9] Azhari, Rishan. "Teaching Descriptive Writing by Using Pictures among the Third Grade Students of SLTP Negeri 18 Malang." Unpublished Thesis. State University of Malang, (2004).

[10] Babbie, Earl. "The Basic of Social Research." California: Zhacomson Wadsworth, (2005).

[11] Belhiah, Hassan, and Maha Elhami. "English as a Medium of Instruction in the Gulf: When Students and Teachers Speak." Language Policy 14.1 (2015): 3-23.

[12] Brown, H. D. "Language Assessment: Principles and Classroom Practices." San Francisco, Person Education, 2004.

[13] Brown, H. Douglas. "Principles of Language Learning and Teaching". San Francisco: Addison Wesley Longman, Inc, (2000).

[14] Chesla, Elizabeth. "Read Better, Remember More (2nd ed.)". New York: Learning Express. (2000).

[15] Cohen, L., Manion, L., \& Morrison, K. "Research methods in education (5th ed.)." Routledge Falmer, New Fetter Lane: London, (2000).

[16] Gay, L. R., and Airasian, Peter. "Educational Research: Competencies for Analysis and Application". Upper Saddle River: Merrill Prentice Hall, (2000).

[17] Haron, Sueraya Che, et al. "Challenges in Learning to Speak Arabic." Journal of Education and Practice 7.24 (2016): 80-85.
[18] Karsono, Puguh. "Using Pictures in Improving the Speaking Ability of the Grade Eight-A Students of SMP Negeri 1 Anggana." Dinamika Ilmu 14.2 (2014): 190-213.

[19] Lukitasari, Nunik. "Students' Strategies in Overcoming Speaking Problems in Speaking Class". Unpublished thesis. University of Muhammadiyah Malang, (2003).

[20] Natasha. "How to Asses Speaking Skills." Cambridge: Cambridge University Press, (2006).

[21] Richards, Jack, C. "Teaching Listening and Speaking from Theory to Practice." New York: Cambridge University, (2008).

[22] Rochmah, Dewi. "The Effect of Using Pictures in a Reading Text on the Student's Comprehension of the main Idea." Unpublished Thesis. State University of Malang, (1996).

[23] Sarip, Mohamad, Zainal Rafli, and Aceng Rahmat. "Arabic Speaking Material Design Using Content and Language Integrated Learning (CLIL)." International Journal of Humanities and Cultural Studies (IJHCS) 5.1 (2018): 272-286.

[24] Sinclair, John. Collins. COBUILD English Language Dictionary. London, Harper Collins Publishers, 1987.

[25] Tanveer, Muhammad. "Investigation of the Factors that Cause Language Anxiety for ESL/EFL Learners in Learning Speaking Skills and the Influence it Casts on Communication in the Target Language." Master thesis. University of Glasgow, (2007)

[26] Urrutia Leó, William, and Esperanza Vega Cely. "Encouraging Teenagers to Improve Speaking Skills through Games in a Colombian Public School." Profile Issues in Teachers Professional Development 12.1 (2010): 11-31. 